SAND80-7015

Unlimited Release

UC-60 Distribution

\title{
Vertical Axis Wind Turbine Foundation \\ Parameter Study
}

\section{P. F. Ludde}

University of New Mexico

Prepared for Sandia National Laboratories under Contract No. 13-8731

Prepared by Sandia National Laboratories, Albuquerque, New Mexico 87185

and Livermore, California 94550 for the United States Department of Energy

under Contract DE·AC04-76DP00789

Printed July 1980

\section{Sandia National Laboratories}

When printing a copy of any digitized SAND

Report, you are required to update the markings to current standards. 
Issued by Sandia Laboratories, operated for the United States Department of Energy by Sandia Corporation.

\section{NOTICE}

This report was prepared as an account of work sponsored by the United States Government. Neither the United States nor the Department of Energy, nor any of their employees, nor any of their contractors, subcontractors, or their employees, makes any warranty, express or implied, or assumes any legal liability or responsibility for the accuracy, completeness or usefulness of any information, apparatus, product or process disclosed, or represents that its use would not infringe privately owned rights.

Printed in the United States of America

Available from

National Technical Information Service

U. S. Department of Commerce

5285 Port Royal Road

Springfield, VA 22161

Price: Printed Copy $\$ 4.50$; Microfiche $\$ 3.00$ 
SAND 80-7015

Unlimited Release

Printed March 1980

VERTICAL AXIS

HIND TUREINE FCUNDATION

PARAMETER STUDY

\author{
Peter F. Lodde \\ Geotechnical Division \\ Civil Engineering Research Facility \\ University of New Mexico \\ Albuquerque, New Mexico 87131
}

Apri1 1980

ABSTRACT

The dynamic failure criterion governing the dimensions of prototype Vertical Axis Wind Turbine Foundations is treated as a variable parameter. The resulting change in foundation dimensions and costs is examined. 


\section{CONTENTS}

$\begin{array}{lc}\text { Introduction } & \text { Page } \\ \text { 1. Overview } & 1 \\ \text { 2. Summary of Previous CERF Investigation } & 1 \\ \text { 3. Objective and Outline of Parameter Study } & 2 \\ \text { Dynamic Failure Criteria for Foundation Design } & 3 \\ \text { 1. Choosing a Failure Criterion } & 4 \\ \text { 2. Failure Criteria for VAlT Foundations } & 4 \\ \text { Approach and Results of Parameter Study } & 8 \\ \text { 1. Approach of Parameter Study } & 8 \\ \text { 2. Results of Parameter Study } & 10 \\ \text { 3. Other Computations }\end{array}$

References 


\section{ILLUSTRATIONS}

Figure

Page

1. Dynamic Design Curve, 300 Ft. VAWT

9

2. Parametric Design Curves, $82.5 \mathrm{Ft}$. VAllT

11

3. Parametric Design Cruves, 112.5 Ft. VAWT 12

4. Parametric Design Curves, $150 \mathrm{Ft}$. VAWT 13

5. Parametric Design Curves, 225 Ft. VAWT 14

6. Parametric Design Curves, $300 \mathrm{Ft}$. VAWT 15

\section{TABLES}

Table

Page

I VAWT Foundation cost Estimates

13 


\section{INTRODUCTION}

\section{Overview}

The Federal Government is committed to developing clean, cost competitive sources of energy. At the present time wind energy is one of the primary sources of interest; not only is there an immense reservoir of untapped wind energy available to the United States, but wind is perhaps the most environmentally acceptable of al1 sources. The United States Department of Energy (DOE), the lead agency in the government's energy development program has funded numerous windenergy conversion systems for demonstration and evaluation.

One of the systems under evaluation is the Vertical Axis lind Turbine (VAWT) - a turbine having its rotating shaft transverse to the flow of the wind, that is in a vertical orientation. The original concept for such a turbine is attributed to the Frenchman, G.J.M. Darrieus, who in 1925 applied for a United States patent for his design of a vertical axis wind turbine and was granted a patent in 1931. ${ }^{1}$ The vertical axis wind turbine has certain advantages (and disadvantages) relative to other kinds of wind-energy conversion systems. ${ }^{2}$ In view of modern technology and modern energy needs Darrieus' concept is of significant interest to the DOE.

In 1976, DOE funded Sandia Laboratories to erect and operate a 17-meter Darrieus-type power generation research system. This system has been in operation since March, 1977. It has been used experimentally to demonstrate and evaluate aerodynamic, structural, and system-design concepts. The knowledge gained from experience with this prototype VAWT has made an extension of the VAWT development program feasible, so that recentiy Sandia Laboratories has been studying VAWT systems ranging from 80 to 300 feet in height. As part of this study an investigation was undertaken by the Civil Engineering Research Facility at the University of New Mexico (UMM/CERF), under contract from Sandia Laboratories, to identify the foundation/anchor requirements for the 
range of VAWT designs being considered. ${ }^{3}$ The objective of the CERF investigation was to ensure that sufficient information was available to select, design, and provide cost estimates for the geologic conditions which may be encountered at potential VAWT sites.

2. Summary of Previous CERF Investigation

The CERF investigation (Reference 3) determined appropriate dimensions for, and types of foundation/guy-cable anchor systems for different size vertical axis wind turbines situated on four catagories of idealized soils. The costs of the various foundation/anchor systems was also estimated.

The foundations were designed to adequately resist both static and dynamic loadings due to the weight of the foundation, the weight of the turbine structural components, aerodynamic loads, seismic loads, torsional loads due to emergency braking, and gale force wind loads. The static design procedures resulted in a foundation dimensioned to ensure that stresses induced in the soil were low enough to preclude escessive settlement and bearing capacity failures. The dynamic design procedures resulted in a foundation dimensioned to 1 imit dynamic displacement of the foundation which might lead to failure of the VAWT structural components, including the foundation.

The dynamic design was "driven" by the selection of a dynamic failure criterion, in this case, a maximum allowable displacement of the foundation caused by dynamic loads. Based on standard civil engineering practice a failure criterion of .01 inch displacement was selected. As a result of this choice of failure criterion, for all sizes of VAlTS considered and for all soil conditions, the foundation dimensions were governed by the dynamic design; the recommended foundations were larger, and therefore more costly, than those required to adequately resist static loads.

An important question then, is how variation in the chosen dynamic failure criterion would effect the size and cost of the VAWT foundations. There are reasons to suspect that dynamic failure criterion chosen on the basis of standard civil engineering practice are too conservative 
when applied to VABT design. It is to be expected that a relaxation of the dynamic failure criterion would result in smaller, hence less expensive, VAl:T foundations. At some point a less stringent fajlure criterion will cause the VAUT foundation dimensions to be governed solely by static design requirements, thus the cost of the VAWT foundations would be minimized. It should be noted that the foundation costs for the VAHT systems currently under consideration can be quite large. For instance, the foundation for the 225 foot yn!? system is estimated to cost between $\$ 13,000$ and $\$ 34,000$, depending upon soil conditions. 3 Thus VAUT foundations can utilize an appreciable fraction of the total system expenditures. If the VAWT wind energy systems are to be economically competitive with other energy sources it is imperative that these foundation costs be minimized.

\section{Objective and Cutline of Parameter Study}

The objective of the study reported herein was to treat the dynamic failure criterion as a variable parameter so that the impact of the failure criterion on VAlT foundation size and cost could be estimated.

The succeeding section of this report discusses the philosophy and procedures for selecting a dynamic failure criterion. The limitations of current civil engineering practice applied to VAUT foundations are discussed.

The third section of this report presents the results of the parameter study. Displacements of .01 inch, .04 inch, .08 inch, and .16 inch were chosen as dynamic failure criteria for the VAWT systems considered in Reference 3. The VAWT foundation sizes satisfying these criteria, and their costs, are compared to the sizes and costs recommended in Reference 3. The section clloses with comments concerning supporting calculations performed during the course of this study.

The final section makes recommendations for assessing realistic VAWT dynamic failure criteria through the instrumentation and experimental investigation of a full-scale prototype VAWT system. 


\section{DYNAMIC FAILURE CRITERIA}

FOR FOUNDATION DESIGN

1. Choosing a Failure Criterion

As mentioned previously, VAWT foundation dimensions recommended in Reference 3 were controlled by the dynamic rather than the static design. That is, the foundation dimensions required were greater than those necessary to prevent failure from excessive settlement or bearing collapse of the underlying soils. The dynamic designs were controlled by a dynamic failure criterion. Establishment of the failure criterion is "probably the most important step in the dynamic foundation design process. The failure criterion defines the problem to be solved and is the gage by which we judge the computed solution and, if possible, our measurements of the prototype performance." 4

Despite the recognized importance of selecting a proper dynamic failure criterion the civil engineer designing other than orthodox machine foundations has few guidelines to aid him in making a selection. There are two notable exceptions. When the design of a foundation-soil system involves the consideration of people in the immediate vicinity, adequate guidelines for choosing a dynamic failure criterion have been established. Human tolerances to vibrations have been studied by subjecting people to vibrations as they stood ona shaking table (Reiher and Meister, 1931, Reference 5). The human tolerance limits of Reiher and Meister have been confirmed by subsequent investigations and are generally accepted as useful physiological vibration limits for people. A comprehensive discussion of the effect of vibrations on man can be found in Reference 6 . The second exception involves the design of foundations for precision equipment such as optical laser or computer systems for which rigid motion tolerances have been established.

For commonly encountered machine foundation problems involving generators, pumps and the like, the dynamic design criterion related to 
the operation of the machinery depends on the prime function of the entire instailation and the importance of each machine unit to this function. Thus, the design criterion involves consideration of initial cost, cost of maintenance (including the economic significant of "down" time) and the cost of replacement of the unit. For common types of rotating machinery, for instance electric motors, fans, and machine shop tools, enough information has been collected to establish permissable amplitudes of motion at the operating speed of the equipment. For instance, the paper by Blake (1964) presents guidelines for machines commonly found in chemical manufacturing environments. ${ }^{7}$ In the previous investigation of VAWT foundations performed by CERF, a dynamic failure criterion was chosen from a plot in Blake's paper (Figure 5 in Reference 3 ). The information shown in this plot is typical of failure criterion guidelines presented in books commonly used by civil engineers in this country for designing foundations. ${ }^{4}, 8$

For dynamically loaded foundations the criteria are described in terms of limiting values of acceleration, velocity, or displacement. The limiting values of these quantities which define failure have been determined, as they must be, in an experimental, or empirical fashion. Case studies of structures that have failed, model studies, and sometimes tests of new structures, provide a data base from which failure criteria have been developed. Unfortunately, this data base seems limited as much of the data is either subjective, incomplete, or poorly documented. In addition, data is included for structures with significantly different configurations and operating environments, so that use and interpretation of the conglomerated data is difficult. Still, in the absence of instrumentation studies on prototypes of the structure of interest, civil engineers have no recourse but to design foundations based upon their interpretation of the data.

One might suppose that extensive efforts are underway for expanding and improving the data base, however, such is not the case. The instrumentation of foundations and the documentation of their measured performance is not easy, glamorous, or profitable. For most civil 
engineers, after a structure is erected the work is over. The curious few who want to place instruments on a completed structure are, in most instances, considered to be nuisances more than anything else. The client is not usually anxious to spend additional funds to instrument a structure that is guaranteed in writing to be structurally sound: he wishes instead to see the structure in full operation. Even a curious engineer may be reticient to ask, for somehow talk of monitoring and instruments implies the existence of minute but insidious cracks, or a lack of professional confidence in analytic procedures.

Civil Engineers, like most men, are a prudent lot, always on guard against those who mumble behind their backs, acts of God, and in particular, against swift and agressive legal action. They are asked to design structures founded in the earth based upon what they see in, or pull out of, a single borehole. They compute and design with techniques they know to be simple approximations while seldom receiving the pleasure (or pain) of comparing their computations to reality. Consequently, large safety factors necessarily abound and a prudent man would suspect that dynamic failure criteria established by design engineers are rather on the conservative side.

2. Failure Criteria for VAWT Foundation

It is difficult to choose a dynamic failure criterion for the range of VAWT systems considered in Reference 3. No case histories of the foundation performance of such structures are available.* In addition, cost of maintenance, significance of "down" time, and cost of replacement have not been established. It is clear that VAWT systems will probably be located in remote areas, hence stringent failure criteria necessary when people are present are not required. Furthermore, as mentioned previously, conservatism should not be the light guiding the design of

* As a matter of interest, analysis of the 17-m VAWT system foundation at Sandia Laboratories, using the procedures outlined in Reference 3 show the foundation design to be overly conservative. 
VAWT foundations - minimization of the foundation costs should be the goal. The foundation systems recommended in Reference 3 reflect this fact; they were designed based on a failure criterion somewhat larger than that suggested by standard design practice.

According to Barkan, a Russian expert on foundation vibrations, "It is extremely difficult to establish a limit for the permissable amplitude of foundation vibrations on the basis of general principles."9 Barkan, however, does suggest some general guidelines for use in designing foundations in unusual or unstudied circumstances: "There are some cases in which vibrations with an amplitude of up to 0.4 to $0.5 \mathrm{~mm}$ (.016 to .020 inches) did not have any harmfut effects. However, many cases have been observed in which foundations under engines with low frequencies underwent vibrations at smaller amplitudes than those cited above, but induced strong vibrations of structures located at several tens of meters. . . . . On the strength of data gained by experience it is possible to state that amplitudes of vibrations of a foundation should not exceed 0.10 to $0.25 \mathrm{~mm}$ (.0078 to .0098 inches)." 9 Thus, Barkan supports the failure criterion of .01 inch utilized in Reference 3 while admitting cases where amplitudes of .02 inch might be permissable.

It seems that the best approach for selecting a failure criterion for the VAWT systems under consideration is to base the foundation dimensions on a variable failure criterion. A displacement of .01 inch should be the minimum value of the failure criterion. Larger values should be tested with the realization that foundations dimensioned using a failure criterion larger than .02 inch may be unsound. 


\section{APPROACH AND RESULTS OF}

\section{PARAMETER STUDY}

\section{Approach of Parameter Study}

The approach used in the parameter study was a simple extension of the dynamic design technique employed in the original VAWT foundation study (Reference 3 ). That is, an analytic technique developed by Beredugo and Novak was used to compute the size of a square foundation, of given depth, required to limit the foundation dynamic displacement to the amplitude defined by a failure criterion. Failure criteria of .02 inch, .04 inch, .08 inch, and .16 inch, were chosen. All VAWT system specifications and dynamic loads were defined by Sandia Laboratories and are given in Reference 3. Each failure criterion was exercised over a range of soil shear moduli from 3000 to 15000 psi so that foundation dimensions over a range of soil conditions could be determined. This is the same approach used in Reference 3, except, of course, in the previous study only one failure criterion, .01 inch, was employed. Figure 1 shows a dynamic design curve generated in the previous study.* It is applicable to the $300 \mathrm{ft}$. VAWT configuration currently under consideration by Sandia Laboratories. For a given soil condition (defined in dynamic circumstances strictly by the value of the shear modulus), a size and depth of foundation required to meet the failure criterion is given. The purpose of the parameter study is to produce a family of curves, one for each failure criterion, and overlay them on the dynamic design curves presented in Reference 3 , of which Figure 1 is an example. This is to be accomplished for each of the five VAWT configurations considered

* This figure is included not just to represent a typical result to be found in Reference 3 . In the course of this parameter study the dynamic design curves for the .01 inch failure criterion were recomputed the curve reported in Reference 3 for the 300 feet VAWT was found to be in error. The dynamic design curve in Figure 1 is the correct curve for the 300 feet VAWT. All other design curves reported in Reference 3 were found to be correct. 


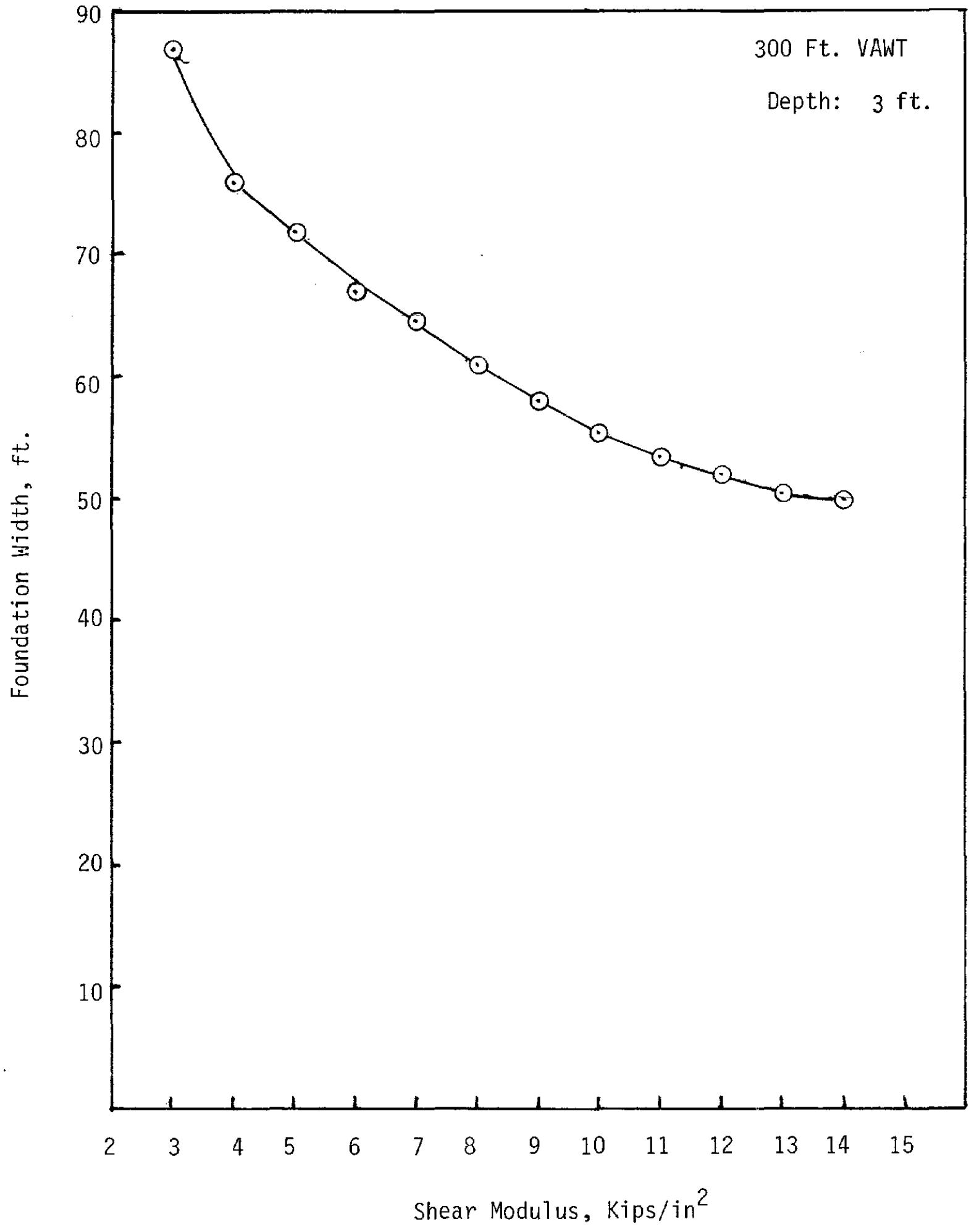

Figure 1 - Dynamic Design Curve, $300 \mathrm{ft}$. VAllT 
in the original study

In engineering practice dynamic foundation analyses are frequently based on a single degree of freedom (SDOF) model. However, this is generally not a good approach for cases when rocking or sliding are present (as in the VAlIT configurations being considered); for the presence of one causes the other. The foundation motion in such cases is coupled and has two degrees of freedom. The analytic technique developed by Ceredugo and llovak accounts for this coupled motion. 10 The technique has another potential advantage; the common theory of foundation vibrations greatly overestimates the real response of the foundation and neglects the fact that the foundations are partly embedded. Beredugo and Novak attempt to account for the effect of this embeddment. Consequentiy, it is hoped that use of their technique will result in not only more accurate calculations than those used from conventional SDOF analyses, but less conservative ones as well.

2. Results of the Parameter Study

Figures 2 through 6 show the results of the parameter study. For each size VAWT system (size referring to the total height of the VAUT tower), a family of solid curves is given, one for each of the specified dynamic displacement criterion. Also shown on each figure is a curve defining the foundation dimensions required to meet the static design requirements for cohesive soils (dashed line) and granular soils (dotted line). The static dimensions are taken from the static design curves given in Section VII and Appendix $C$ of Reference 3. The static dimensions given in Reference 3 are a function of unconfined compression strength for cohesive soils and standard penetration resistance for granular soils. Hence plotting the static design dimensions on Figures 2 through 6 required a correlation between shear modulus and unconfined compression strength and standard penetration resistance respectively (foundations are considered to be square). A search of the geotechnical literature located no such correlation. Consequently, the correlation implied in defining idealized site conditions in Section II of Reference 3 was utilized. For instance, a typical granular soil was 


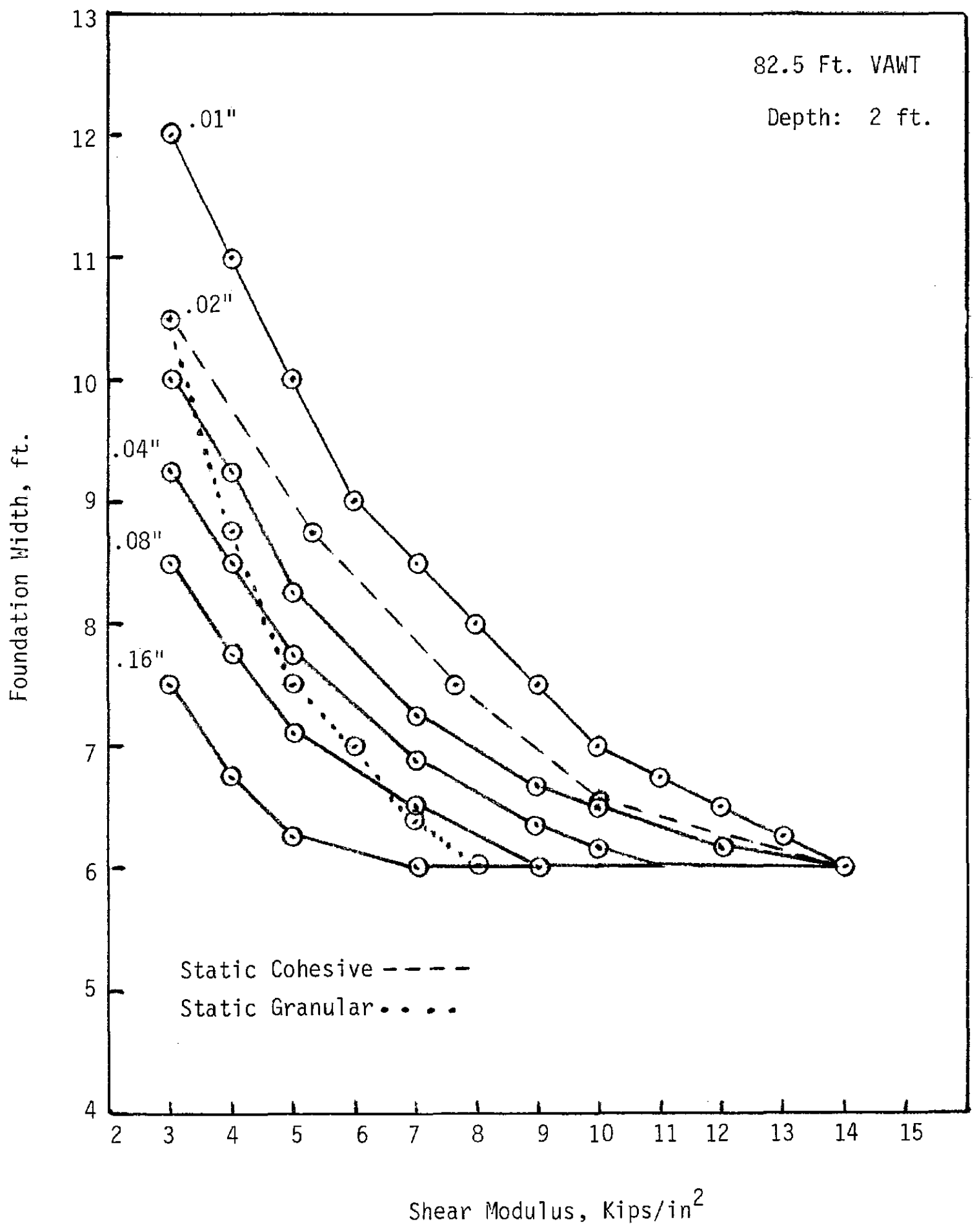

Figure 2 - Parametric Design Curves, $81.5 \mathrm{ft}$. VAlIT 


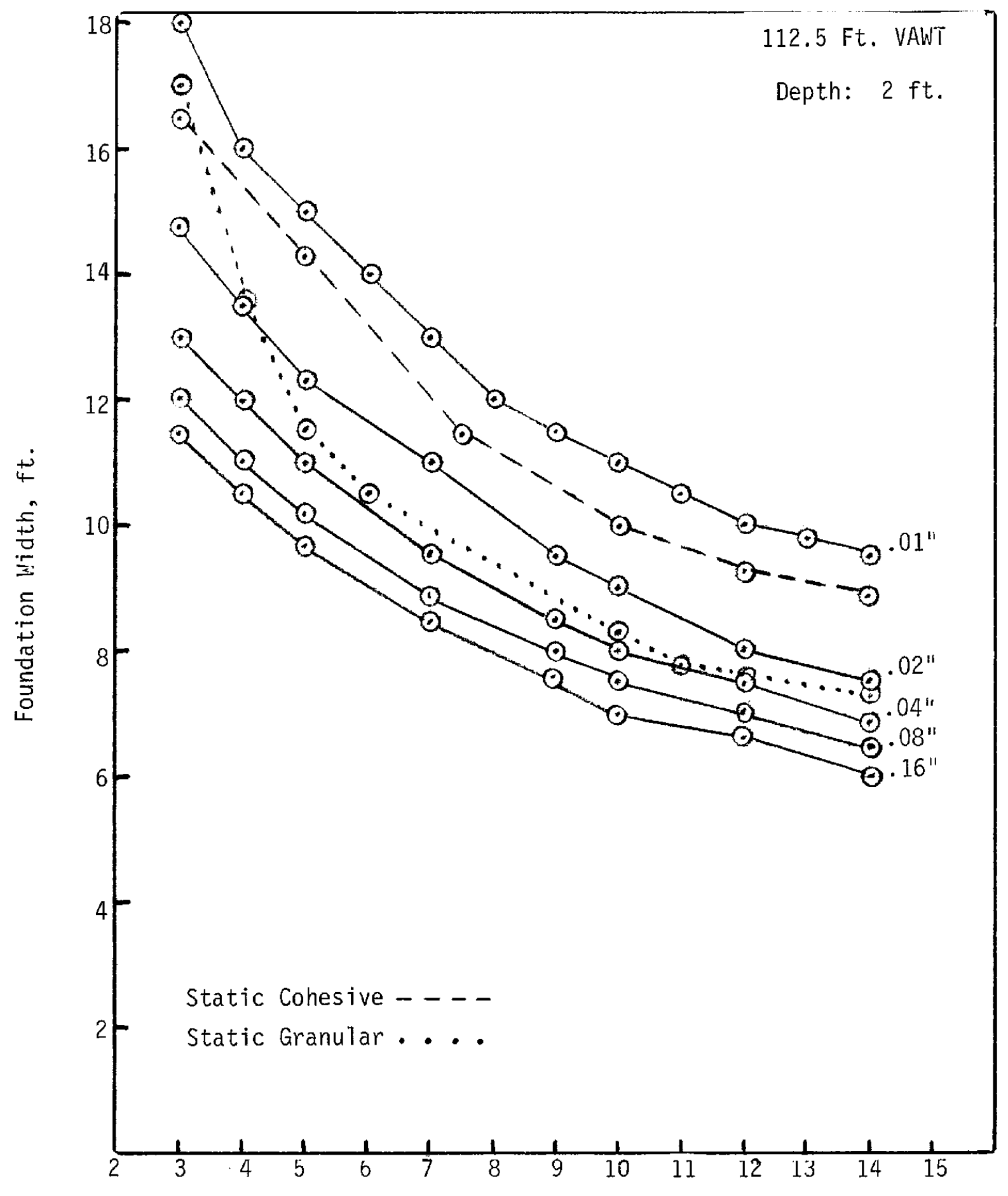

Shear Modulus, Kips/in ${ }^{2}$

Figure 3 - Parametric Design Curves, $112.5 \mathrm{ft}$. VAWT 


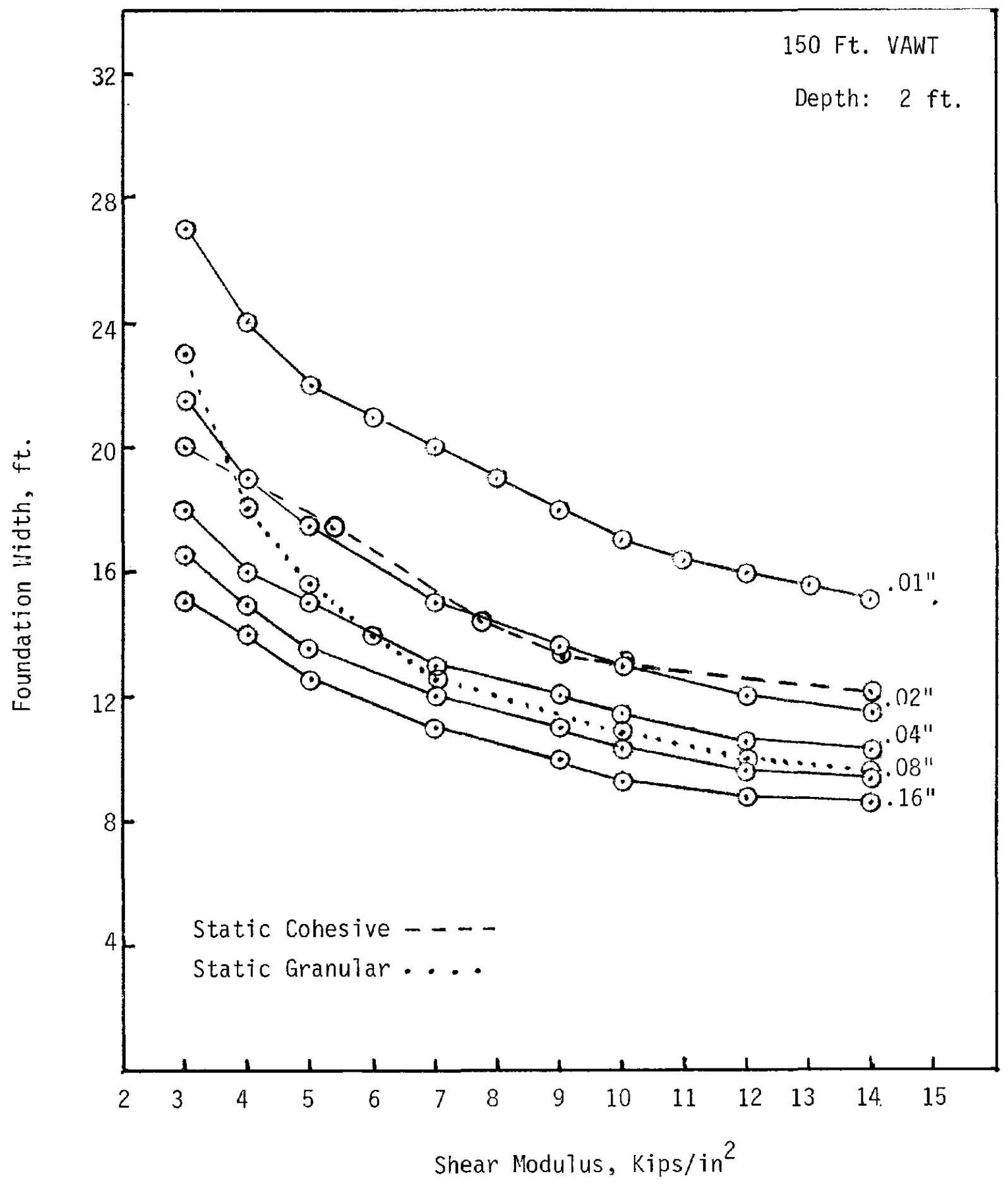

Figure 4 - Parametric Design Curves, $150 \mathrm{ft}$. VAWT 


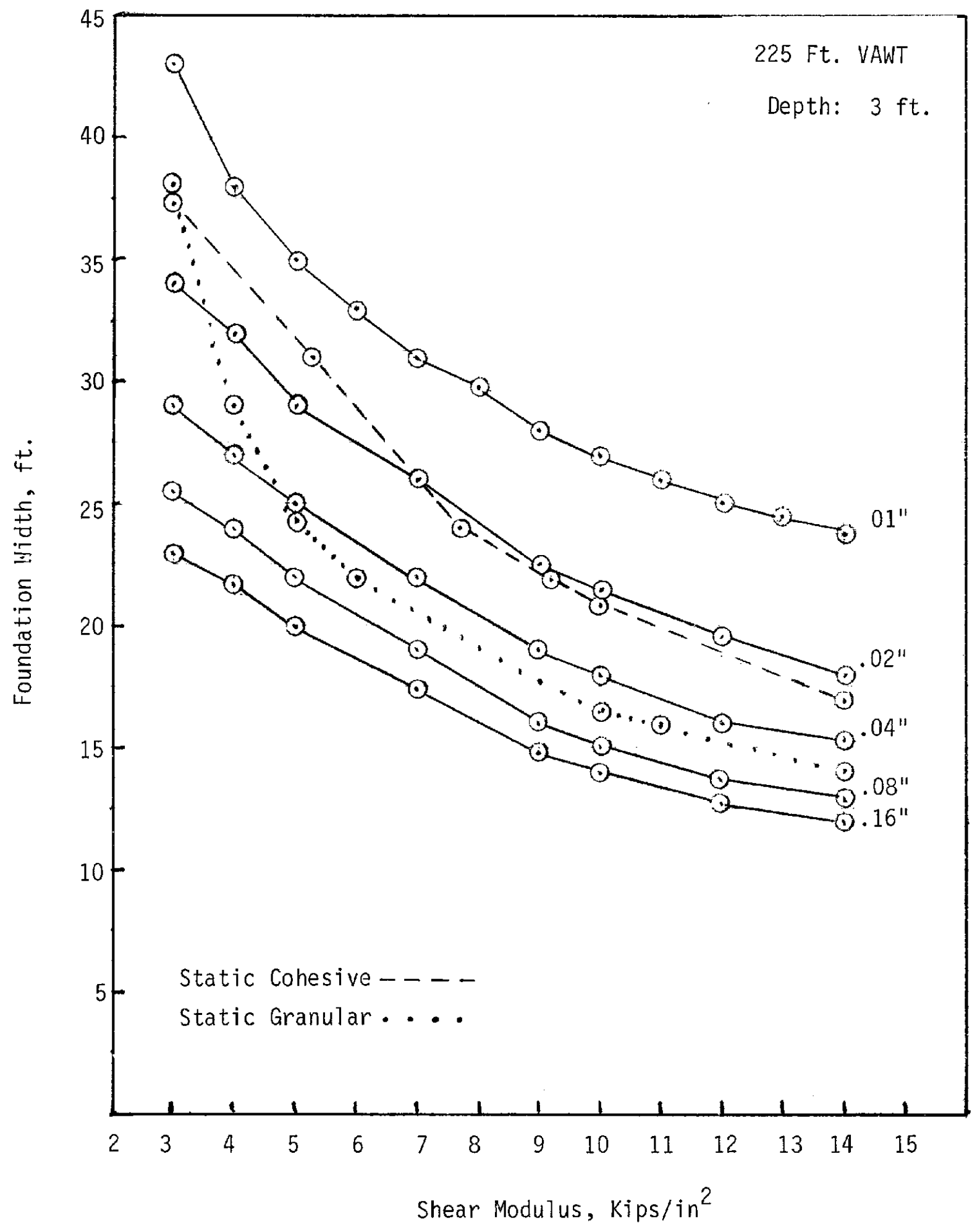

Figure 5 - Parametric Design Curve, $225 \mathrm{ft}$. VAWT 


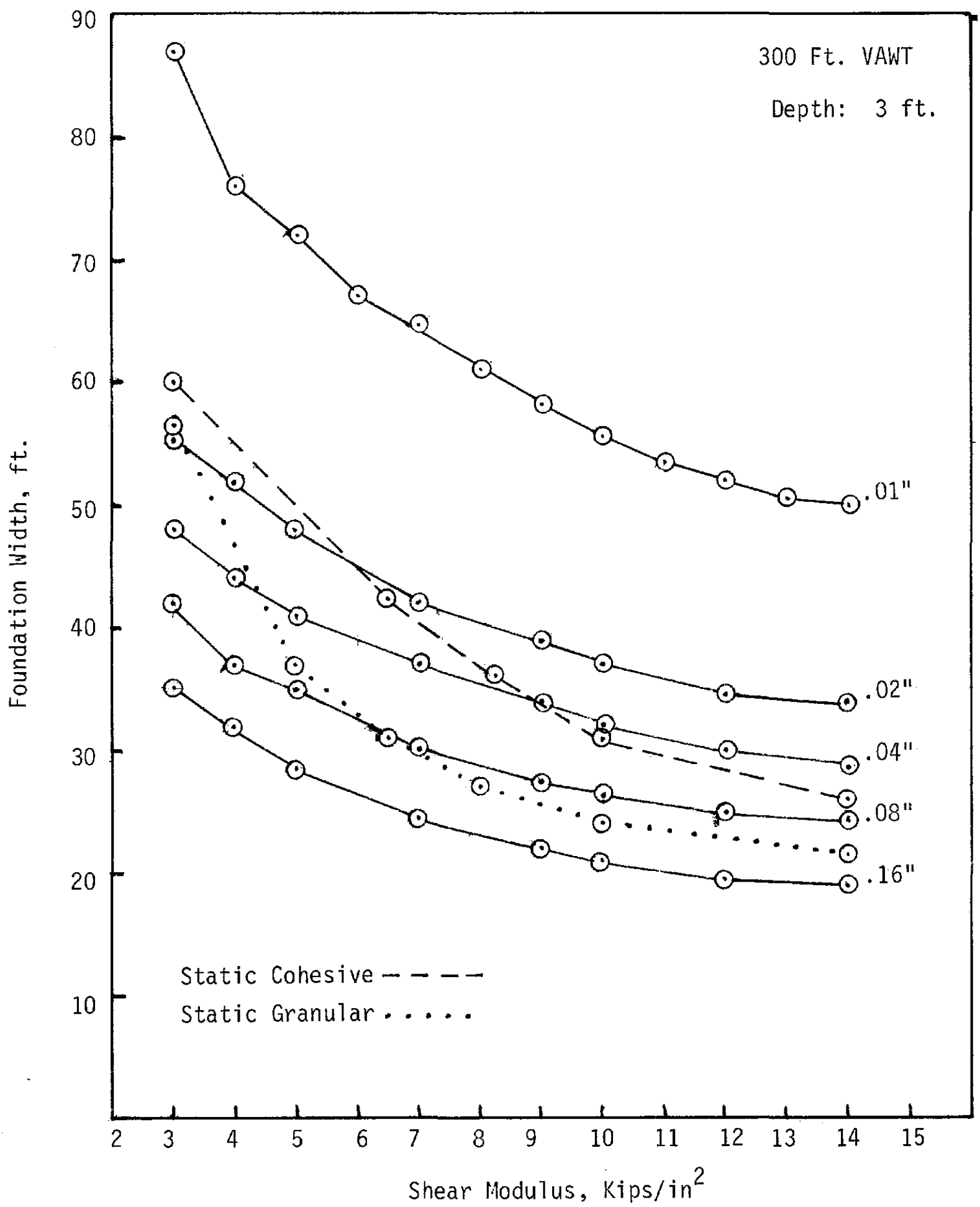

Figure 6 - Parametric Design Curves, $300 \mathrm{ft}$. VAWT 
defined to have a shear modulus of $10000 \mathrm{psi}$ and a standard penetration resistance of 45 blows/feet. On the other hand, a poor granular soil was defined as having a shear modulus of 3000 psi and a standard penetration resistance of 10 blows/feet. A linear interpolation was used to compute the penetration resistance corresponding to a given shear modulus. For instance, a shear modulus of $6500 \mathrm{psi}$ (halfway between 3000 and $10000 \mathrm{psi}$ ) corresponds to a standard penetration resistance of 27.5 blows/feet (halfway between 10 and 45 blows/feet). A similar procedure was used for cohesive soils.

It should be noted that the correlation described was employed due to the lack of more definitive information. A different correlation of course would change the shapes of the static design curves shown in Figures 2-6.

Figures 2 through 6 show graphically what was stated previously: for a failure criterion of .01 inch, the foundation dimensions were governed by the dynamic design requirements, regardless of soil conditions. The figures also show that under general static loading conditions, foundations on granular soils will be smaller than foundations on cohesive soils. This is a fact commonly observed in civil engineering practice.

More importantly, Figures 2 through 6 show that for poor soil conditions, that is, for a shear modulus of $3000 \mathrm{psi}$, the benefits of a significant relaxation of the dynamic failure criterion cannot practically be realized; between .01 inch and .02 inch dynamic displacement static design requirements govern the foundation dimensions. This is true for both cohesive and granular materials except in the case of the 150 feet VAlIT (figure 4). In this case the .02 inch failure criterion is exercised prior to the static, cohesive design requirements.

Extension of the dynamic failure criterion to .02 inch, then, causes the static design requirements to govern in most instances, for foundations on poor soils. A further relaxation of the dynamic failure criterion above .02 inch will not result in a further reduction of the sizes of 
VAWT foundations on poor soils. A similar situation occurs for VALT foundations on typical, or stronger, cohesive soils (shear modulus of 10000 psi or greater). Uith the exception of the 300 feet VAWT (Figure 6), the dimensions required by static design and those required by the dynamic design based on a failure criterion of .02 inch are either quite similar or governed by the static design (Figure 3 ).

On typical granular soils, however, the static design does not govern until large dynamic displacements are allowed. For instance, for the 300 feet VAllT (Figure 6) the static design does not govern unti1 dynamic displacements of over .10 inch (estimated) are allowed. Based on the previous discussion in Section II it is not expected that dynamic displacements of this magnitude will be permissable, so that VAWT systems on competent, typical granular soils will most probably be governed by dynamic design requirements. Since it is reasonable that VAWT systems constructed in the Southwestern United States will be founded on such soils it is important to establish a realistic maximum dynamic failure criterion for VAWT systems. Such a determination can only be made through experimental programs and long term experience with VAUT systems.

The most sensible way to extract meaning from this parameter study is to assume the most reasonable maximum dynamic failure criterion, size VAWT foundations based on this criterion, and then compare the costs of these foundations with the costs of the VAWT foundations presented in Reference 3 . The most reasonable maximum failure criterion, based on the above discussion is clearly .02 inch. Table I shows the estimated costs of VAWT foundations based on this criterion, the information contained in Figure 2-6, and the cost estimation procedure outlined in Reference 3. The numbers in parentheses in Table I are the estimated foundation costs based on the .01 inch failure criterion and reported in Reference $3^{*}$, and the other numbers are the estimated foundation costs

* Except of course, the numbers for the 300 feet VAWT reported in Reference 3. As mentioned previously these numbers were found to be incorrect. Correct values are given in Table I. 


\begin{tabular}{|c|c|c|c|c|}
\hline \multirow{2}{*}{ TOWER SIZE (ft.) } & \multicolumn{2}{|c|}{ COHESIVE SOIL } & \multicolumn{2}{|c|}{ GPANULAR SOIL } \\
\hline & POOR & TYPICAL & POOR & TYPICAL \\
\hline 82.5 & $2286(2800)$ & $614(1192)$ & $2286(2800)$ & $614(1192)$ \\
\hline 112.5 & $3837(4900)$ & $1478(2339)$ & $4065(4900)$ & $1016(2339)$ \\
\hline 150 & $7228(10150)$ & $2286(4305)$ & $7843(10150)$ & $2120(4305)$ \\
\hline 225 & $27178(34100)$ & $9698(13042)$ & $27178(34100)$ & $9698(13042)$ \\
\hline 300 & $70036(142000)$ & $27178(34633)$ & $63318(142000)$ & $27178(34633)$ \\
\hline
\end{tabular}

NOTE: First figure is foundation cost for .02" fialure criterion. Figure in parentheses is cost for .01" failure criterion. 
based on .02 inch failure criterion.

The table shows that based on the .02 inch criterion, in general only moderate reduction in VAWT foundation costs can be expected. The exception is for the $300 \mathrm{ft}$. VAWT systems founded on poor soils, where foundation costs might be reduced by $50 \%$ or more. However, as detailed in Reference 3, construction of this VAUT on poor cohesive soil is not recommended; 1arge settlements will result.

Cost estimates based on failure criteria larger than .02 inch can be performed by the reader using Figures 2-6, and the cost estimating procedure in Reference 3. Such estimates for VNUT foundations on poor soils will remain as shown in Table I as static design requirements govern the foundation dimensions. Estimates for soils on typical soils will change significantly. However, it is recommended that such estimates be used with care, as foundations based on large failure criterion will probably never be constructed.

Several final comments should be made. First, the dynamic design curves shown in Figures 2-6 exhibit an interesting feature; the smaller tre criteria defining failure the greater the increase in foundation size required to allow a unit incremental reduction in the criterion. For instance, in Figure 5, the foundation width required to allow a dynamic displacement of .16 inch is 23 feet; a reduction in the failure criterion by .08 inch to .08 inch requires a foundation width of 26 feet. Yet a reduction in the dynamic failure criterion from .02 inch to .01 inch, a reduction of only .01 inch, requires the foundation width to increase from 34 feet to 43 feet. This feature of the dynamic design curves is explained by the fact that as the VAWT foundations become larger their natural frequencies begin to approach the low operating frequencies typical of these large VAWT systems. That is, as the foundation sizes are increased, a condition of resonance is approached.

Finally, it has been determined, as part of the previous CERF study, that foundations based on static design requirements are sufficient to 
withstand not only the static loads on the foundation but dynamic loads other than those associated with aerodynamic loads present during normal VAWT operations. These loads include gale force wind loads, earthquake loads, and torsional loads due to emergency braking. Consequently, VAWT foundations governed by a dynamic failure criterion, whatever its magnitude, will be sufficient for resisting these same loads.

3. Cther Computations

Conventional analyses of foundation-soil system motions are based on lumped parameter approaches in which the system is usually assummed to have a single degree of freedom. Techniques based on this approach are described in the standard soil dynamics texts (for instance Reference 4). Vertical, horizontal, rocking, and torsional motions of foundations can be analyized using these techniques. There are many cases studies in which the SDOF approach to dynamic foundation design have been shown to give acceptable, even accurate predictions of foundation motions and resonant frequencies. ${ }^{4}, 1:, 12$

Few case studies exist, however, documenting the efficacy of the lumped parameter, two degree of freedom analysis of foundations subjected to rocking and sliding. In particular, the method developed by Beredugo and Novak has not been conclusively tested in engineering practice. Beredugo and Novak have tested the method against results of experimental tests on models; good agreement between measurements and theory was obtained. 10 Higgins has used the method to accurately predict the resonant frequency of a structure subjected to an explosively induced simulation of an earthquake.13

An effort was made to analyize the VAWT systems in SDOF sliding and rocking to get an independent check on the results obtained using the method of Beredugo and Novak. In several instances the SDDF analysis predicted vertical displacements very similar to those predicted by the two DOF analysis. In other cases the SDOF predicted vertical displacements which were relatively much greater. SDOF analyses used to predict horizontal sliding motions gave erratic results; most disturbing were several instances in which estimation of SDOF equivalent damping parameters caused terms of which square roots were to be taken to have negative 
values, a clear sign that use of the simple SDOF approaches to analyize VAUT foundations is in inappropriate. Attempits were made to allow the vertical SDOF calculations to account for damping due to embeddment, using techniques developed by Stokoe. ${ }^{14}$ However, this did not result in better agreement with the parameter study computations. In summary, efforts to assess the VAWT parameter study computations using SDOF approaches were inconclusive.

The computations based on the method of Beredugo and Novak did have one other interesting feature - the predicted horizontal displacements of the VAWT foundations were always larger than the predicted vertical displacements. The calculated horizontal displacements were consistently 2 to 3 times larger than the calculated vertical displacements. That is, the VAWT foundation dimensions were driven by the horizontal displacements. Whereas vertical displacements can only be 1 imited by increasing the area of a foundation, horizontal displacements, particularly when sliding is present, can be 1 imited by constructing keys on the bottom of the foundation. The key is simply a wall-like extension of the foundation into the ground, much like the keel of a sailboat. The VAliT foundation dimensions shown in Figures 2 through 6 could be considerably smaller and still provide adequate resistance against dynamic vertical displacements. Perhaps a keyway structure would allow the foundations to retain these smaller dimensions while still providing adequate limitation of the dynamic horizontal displacements. A significant cost savings might be realized, particularly if a very small failure criterion is necessary.

It is not clear, however, that the horizontal displacements predicted in the parameter study are entirely real. Certainly, the analytic model of Beredugo and Novak allows no sliding of the foundation relative to the elastic half-space upon which it is assummed to rest. The computed horizontal displacements are due entirely to a shearing deformation in this half-space. The model gives no estimate of the motion field produced below the foundation, consequently there is no method for estimating the necessary depth of a keyway designed to limit horizontal motions. A further study of this problem would require another approach, possibly a 
series of finite-element calculations. Such an approach was beyond the scope of this study. 


\section{Conclusions and Recommendations}

\section{Computations and Reality}

The goal of this parameter study would have been simplified considerably if the static design governed to the VAUT foundation dimensions for all choices of a dynamic failure criterion. The design of foundations to resist static loads is based upon well-established principles that have been confirmed by many years of engineering practice.

Because the VAWT foundation designs appear to be driven by dynamic failure criterion many questions arise, and these questions, especially for such a unique application, are difficult to answer. As previously discussed it is not clear for the VAWT systems what an appropriate dynamic failure criteria should be. Uncertainties, however, are to be found in other places also. The analytic techniques used in computing dynamic foundation response have shortcomings; some of these have already been discussed. Finally, the VAUT system specifications and dynamic loads supplied to CERF by Sandia Laboratories, are not known with absolute precision. Consequently, the results of the computations comprising this parameter study can be expected to deviate, by some unknown amount, from the actual performance of VAWT foundations. This deviation can be assessed only through an experimental program aimed at determining the response of a full scale VAWT foundation under normal operating conditions. Such a program would not only assess the accuracy of the analytic technique employed, but would help establish what the magnitude of dynamic failure criteria for VAWT foundations should be.

It is strongly recommended that the technical problems associated with measuring the response of a VAWT foundation be identified, assessed, and their costs estimated. Once this is accomplished plans should be made for instrumenting the foundation of a prototype VAIIT structure and monitoring its dynamic response, over a significant length of time, and 
over a full range of operating conditions. The results of measurements obtained by this monitoring program should then be compared to the predictions calculated using the methods referred to in Reference 3 and in this report.

In the absence of such an experimental program, or until some other relevant evidence is made available, the VAWT foundations should be designed with at least a modicum of conservatism. It is recommended that the dynamic design curves based on a failure criteria of .01 inch be employed. 


\section{REFERENCES}

1. Darrieus, G.J.M., "Turbine Having Its Rotating Shaft Transverse to the Flow of the Current", United States Patent P'o. 1-835-018, December 1931.

2. Wetherholt, L., et al., "Vertical Axis Wind turbine Technology", Proceedings of the Workshop hosted by Sandia Laboratories, SAND 76-5586, May, 1976.

3. Auld, H.E., and Lodde, P.F., "A Study of Foundation/Anchor Requirements for Prototype Vertical Axis wind Turbines". SAND 78-7046, Sandia Laboratories, Albuquerque, New Mexico, December, 1978.

4. Richart, F.E., Jr., Ha11, J.R., and lioods, R.D., "Vibrations of Soils and Foundations", Prentice-Ha11, Englewood Cliffs, New Jersey, 1970.

5. Reiher, H., and Meister, F.J., "Die Empfindlichkeit der Menschen gegen Erschuttergen," Forsch. Gebiete Ingenieurwesen, Vol. 2, No. 11, pp. 381.386, 1931.

6. Harris, C.M., and Crede, C.E., "Shock and Vibration Handbook," PCGraw-Hill Book Co., 1961.

7. Blake, M.P., "New Vibration Standards for Maintenance", Hydrocarbon Processing and Petroleum Refiner, Vol. 43, No. 1 (Jan.) pp. 111-114, (copyrighted in 1962 by Gulf Publishing Company, Houston, Texas).

8. Winterkorn, H.F., Fang, H.Y., "Foundation Engineering Handbook," Von Nostrand, Reinhold, New York, New York, 1975.

9. Barkan, D.D., "Dynamies of Bases and Foundations," Translated from the Russian by L. Drasheveka, McGraw-Hi11, New York, 1962, originally published in Moscow, 1948.

10. Beredugo, Y.o., and Novak, M., "Coupled Horizontal and Rocking Vibration of Embedded Footings," Canadian Geotechnical Journal, Vol.9, 1972.

11. Margason, B.E., MCNei11, R.L., and Babock, F.M., "Case Histories in Foundation Vibrations," Vibration Effects of Earthquakes on Soils and Foundations, ASTM! STP 450, American Society for Testing and Materials, 1969.

12. MCNei1, R.L., Margason, B.E., and Barnejch, J.A., "Design of Test Pads for Transient Loadings," American Institute of Aeronautics and Astronautics, Vol. Tech. Papers, Guidance and Control Conference (Huntsville), :ew York, 1967.

13. Personal communication with Neil Higgins, currently of Higgins and Auld and Associates, .7 buquerque, New Mexico, March, 1977. 


\section{References}

Continued:

14. Stokoe, K.H., II, and Selcuk, E.M., "Effects of Embeddment on Foundation Response," Draft of paper to be published. 
DISTRTBUTION :

TID-4500-R66 UC-60 (283)

Aero Engineering Department (2)

Wichita State University

Wichita, KS 67208

Attn: M. Snyder

W. Wentz

R. E. Akins, Assistant Professor

Department of Engineering Science and Mechanics

Virginia Polytechnic Institute and State University

Blacksburg, VA 24060

Alcoa Laboratories (5)

Alcoa Technical Center

Aluminum Company of America

Alcoa Center, PA 15069

Attn: D. K. Ai

A. G. Craig

J. T. Huang

J. R. Jombock

P. N. Vosburgh

Mr. Robert B. Allen

General Manager

Dynergy Corporation

P.O. Box 428

1269 Union Avenue

Laconia, NH 03246

American Wind Energy Association

1609 Connecticut Avenue NW

Washington, DC 20009

E. E. Anderson

South Dakota School of Mines

and Technology

Department of Mechanical Engineering

Rapid City, SD 57701

Scott Anderson

318 Millis Hall

University of Vermont

Burlington, VT 05405

G. T. Ankrum

DOE/Office of Commercialization

20 Massachusetts Avenue NW

Mail Station 2221C

Washington, DC 20585

Holt Ashley

Stanford University

Department of Aeronautics and

Astronautics Mechanical Engineering Stanford, CA 94305
Kevin Austin

Consolidated Edison Company of New York, Inc.

4 Irving Place

New York, NY 10003

B. H. Barksdale, Jr.

Hayes, Seay, Mattern \& Mattern

1315 Franklin Road $\mathrm{SW}$

Roanoke, VA 24016

F. K. Bechtel

Washington State University

Department of Electrical Engineering

College of Engineering

Pullman, WA 99163

M. E. Beecher

Arizona state University

Solar Energy Collection

University I,ibrary

Tempe, Az 85281

K. Bergey

University of Oklahoma

Aero Engineering Department

Norman, OK 73069

León Bjervig

Civilingeniф力r, MCIF

"Østerbyhus," 6990 Uleborg

DK6990 DENMARK

Steve Blake

Wind Energy Systems

Route 1, Box 93-A

oskaloosa, KS 66066

Robert Brulle

McDonne11 Douglas Aircraft Corporation

P.O. Box 516

Department 341 , Building $32 / 2$

St. Louis, MO 63166

R. Camerero

Faculty of Applied Science

University of Sherbrooke

Sherbrooke, Quebec

CANADA JIK 2RI

CERCEM (2)

49 Rue du Commandant Rolland

93350 Le Bourget

FRANCE

Attn: G. Darrieus

J. Delassus 
Professor V. A. L. Chasteau

School of Engineering

University of Auckland

private Bag

Auckland, NEW ZEALAND

Howard T. Clark

McDonnell Aircraft Corporation

P.O. Box 516

Department 337 , Building 32

st. Louis, MO 63166

Dr. R. N. Clark

USDA, Agricultural Research Service

Southwest Great Plains Research Center

Bushland, $\mathrm{TX} 79012$

Joan D. Cohen

Consumer outréach Coordinator

State of New York

Executive Department

state consumer protection Board

99 Washington Avenue

Albany, NY 12210

Dr. D. E. Cromack

Associate professor

Mechanical and Aerospace Engineering Department

University of Massachusetts

Amberst, MA 01003

Gale B. Curtis

Tumac Industries

650 Ford street

Colorado springs, co

80915

DOE/ALO (3)

Albuquerque, NM 87185

Attn: G. P. Tennyson

D. C. Graves

D. W. King

DOE Headquarters (20)

Washington, DC 20545

Attn: L. V. Divone, Chief Wind Systems Branch

D. F. Ancona, Program Manager wind Systems Branch

C. W. Dodd

School of Engineering

Southern Illinois University

Carbondale, IL 62901
Dominion Aluminum Fabricating Itd. (2)

3570 Hawkestone Road

Mississauga, Ontario

CANADA L5C 2U8

Attn: L. Schienbein

C. Wood

D. P. Dougan

Hamilton Standard

1730 NASA Boulevard

Room 207

Houston, $\mathrm{TX} \quad 77058$

J. B. Dragt

Nederlands Energy Research Foundation (E.C.N.)

Physics Department

Westerduinweg 3 Patten ( $n h$ )

THE NETHERLANDS

C. E. Elderkin

Battelle-Pacific Northwest Laboratory P.O. Box 999

Richland, WA 99352

Frank R. Eldridge, Jr.

The Mitre Corporation

1820 Dolley Madison Blvd.

McLean, VA 22102

Electric Power Research Institute

3412 Hillview Avenue

Palo Alto, CA 94304

Attn: E. Demeo

James D. Fock, Jr.

Department of Aerospace Engineering Sciences

University of Colorado

Boulder, CO 80309

Dr. Lawrence C. Frederick

Public Service Company of New Hampshire 1000 Elm Street

Manchester, NH 03105

H. Gerardin

Mech. Eng, Dept.

Faculty of Sciences \& Eng.

Université Laval - Quebec

CANADA GIK 7P4

E. Gilmore

Amarillo College

Amarillo, Tx 79100

Paul Gipe

Wind Power Digest

p.O. Hox 539

Harrisburg, PA 17108 
Roger T. Griffiths

University College of Swansea

Department of Mechanical Engineering

singleton Park

Swansea SA2 8PP

UNITED KINGDOM

Professor N. D. Ham

Massachusetts Institute of Technology

77 Massachusetts Avenue

Cambridge, MA 02139

\section{Sam Hansen}

DOE/DST

20 Massachusetts Avenue

washington, DC 20545

C. F. Harris

Wind Engineering Corporation

Airport Industrial Area

Box 5936

Lubbock, TX 79415

W. L. Harris

Aero/Astro Department

Massachusetts Institute of Technology

Cambridge, MA 02139

Terry Healy (2)

Rockwell International

Rocky Flats plant

P.O. Box 464

Golden, CO 80401

Helion

P.o. Box 4301

Sylmar, CA 91342

Don Hinrichsen

Associate Editor

AMBIO

KVA

Fack, s-10405

stockholm

SWEDEN

Sven Hugosson

Box 21048

S. 10031 stockholm 21

SWEDEN

O. Igra

Department of Mechanical Engineering Ben-Gurion university of the Negev Beer-sheva, ISRAEL
Indian oil Corporation, Ltd.

Marketing Division

254-C, Dr. Annie Besant Road

Prabhadevi, Bombay-400025

INDIA

JBF Scientific Corportion

2 Jewel Drive

wilmington, MA 01887

Attn: E. E. Johanson

Dr. Gary L. Johnson, P.E.

Electrical Engineering Department

Kansas State University

Manhattan, KS . 66506

J. P. Johnston

Stanford University

Department of Mechanical Engineering

stanford, CA 94305

B. O. Kaddy, Jr.

Box 353

31 Union street

Hillsboro, NH 03244

Kaman Aerospace Corporation

old Windsor Road

Bloomfield, CT 06002

Attn: w. Batesol

Robert E. Kelland

The College of Trades and Technology P.O. Box 1693

Prince Philip Drive

st. John's, Newfoundland

CANADA AIC 5P7

Larry kinnett

P.O. Box 6593

Santa Barbara, CA 93111

o. Krauss

Michigan State University

Division of Engineering Research

East: Lansing, MI 48824

Lawrence Livermore Laboratory

P.O. BOX $808 \mathrm{~L}-340$

Livernore, CA 94550

Attn: D. W. Dorn

M. Lechner

Public Service Company of New Mexico P.0. Box 2267

Albuguerque, NM 87103 
George E. Lennox

Industry Director

Mill products Division

Reynolds Metals Company

6601 west Broad street

Richmond, VA 23261

\section{J. Lerner}

State Energy Commission

Research and Development Division

1111. Howe Avenue

Sacramento, $\mathrm{CA} \quad 95825$

L. Liljidahl

Builaing 303

Agriculture Research Center

USDA

Beltsville, MD 20705

P. B. S. Lissaman

Aeroenvironment, Inc.

660 South Arroyo Parkway

Pasadena, CA 91105

olle Ljungstrom

FFA, The Aeronautical Research Institute

Box 11021

S-16111. Broma

SWEDEN

Los Alamos Scientific Laboratories

P.O. Box 1663

Los AJamos, NM 87544

Attn: J. D. Balcomb Q-DO-T

Library

Ernel L. Luther

Senior Associate

PRC Energy Analys is Co.

7600 old Springhouse Rd.

McLean, VA 22101

L. H, J, Maile

48 York Mills Rd.

Willowdale, ontario

CANADA M2P $1 B 4$

Jacques R. Maroni

Ford Motor Company

Environmental Research and Energy

Planning Director

Environmental and Safety Engineering Staff

The American Road

Dearborn, MI 48121

Frank Matanzo

Dardalen Associates

15110 Frederick Road

Woodbine, MD 21797
H. S. Matsuda, Manager

Composite Materials Laboratory

Pioneering R\&D Laboratories

Toray Industries, Inc.

Sonoyama, Otsu, shiga

JAPAN 520

J. R. MoConnell

Tumac Industries, Inc.

650 Ford st.

Colorado Springs, CO 80915

James Meiggs

Kaman Sciences Corporation

P.O. Box 7463

Colorado Springs, Co 80933

R. N. Meroney

Colorado State University

Department of Civil Engineering

Fort Collins, co 80521

G. N. Monsson

Department of Economic Planning and Development

Barrett Building

Cheyenne, WY 82002

NASA Lewis Research Center (2)

21000 Brookpark Road

Cleveland, OH 44135

Attn: J. Savino

R. L. Thomas

W. Robbins

K. Kaza

Anthony A. Nedd, President

The Power Co., Inc.

P.O. Box 221

Genesee Depot, WI 53217

V. Nelson

West Texas State University

Department of Physics

P.O. Box 248

Canyon, TX 79016

Leander Nichols

Natural Power, Inc.

New Boston, NH 03070

Oklahoma State University (2)

Stillwater, OK 76074

Attn: W. L. Hughes

EE Department

D. K. McLaughlin

ME Department 
Oregon State University (2)

Corvallis, OR 97331

Attn: R. E. Wilson

ME Department

R. W. Thresher

ME Department

Pat F. O'Rourke

precinct 4

county Commissioner

City-County Building

El Paso, TX 79901

H. H. Paalman

Dow Chemical USA

Research Center

2800 Mitchell Drive

Walnut Creek, CA 94598

R. A. Parmelee

Northwestern University

Department of Civil Engineering

Evanston, IL 60201

Helge petersen

Riso National Laboratory

DK-4000 Roskilde

DENMARK

wilson Prichett, III

National Rural Ezectric Cooperative Association

1800 Massachusetts Avenue NW

Washington, DC 20036

Dr. Barry Rawlings, Chief

Division of Nechanical Engineering

Comnonwealth Scientific and Industrial Research Organization

Graham Road, Highett

victoria, 3190

AUSTRALIA

Thomas W. Reddoch

Associate Professor

Department of Electrical Engineering

The University of Tennessee

Knoxville, TN 37916

A. Robb

Memorial University of Newfoundland

Faculty of Engineering and Applied Sciences

St. John's Newfoundland

CANADA AlC 557
Dr.-Ing. Hans Ruscheweyh

Institut fur Leichtbau

Technische Hochschule Aachen

wullnerstrasse 7

GERMANY

Gwen Schreiner

Librarian

National Atomic Museum

Albuquerque, NM 87185

Arnan Seginer

professor of Aerodynamics

Technion-Israel Institute of

Technology

Department of Aeronautical.

Engineering

Haifa, ISRAEL

Dr. Horst Selzer

Dipl.-Phys.

Wehrtechnik und Energieforschung

ERNO-Raumfahrttechnik GmbH

Hunefeldstr. 1-5

Postfach $10 \quad 5909$

2800 Bremen 1

GERMANY

H. Sevier

Rocket and Space Division

Bristol Aerospace Ltd.

P.O. Box 874

Winnipeg, Manitoba

CANADA R3C $2 S 4$

P. N. Shankar

Aerodynamics Division

National Aeronatical Laboratory Bangalore 560017

INDIA

David Sharpe

Kingston polytechnic

Canbury Park Road

Kingston, surrey

UNITED KINGDOM

D. G. Shepherd

Cornell university

Sibley School of Mechanical and Aerospace Engineering

Ithaca, NY 14853

H. P. Sleeper

Kentin International

2000 Birdspring Road

Huntsville, AL 35802 
Dr. Fred Smith

Mechanical Engineering Department Head Colorado State University

Ft. Collins, Co 80521

Kent Smith

Instituto Tecnológico Costa Rica

Apartado 159 Cartago

COSTA RICA

Leo H. Soderholm

Iowa State University

Agricultural Engineexing, Room 213

Ames, IA 50010

Southwest Research Institute (2)

P.O. Drawer 28501

San Antonio, TX 78284

Attn: W. L. Donaldson, Senior Vice President

R. K. Swanson

Rick Stevenson

Route 2

Box 85

Springfield, MO 65802

Dale T. Stjernholm, P.E.

Mechanical Design Engineer

Morey/Stjernholm and Associates

1050 Magnolia Street

Colorado Springs, co 80907

G. W. Stricker

383 Van Gordon 30-559

Lakewood, CO 80228

C. J. Swet

Route 4

Box 358

Mt. Airy, MD 21771

R. J. Templin (3)

Low Speed Aerodynamics Section

NRC-National Aeronautical Establishment

Ottawa 7, Ontario

CANADA KIA OR6

Texas Tech University (3)

P.O. Box 4289

Lubbock, TX 79409

Attn: K. C. Mehta, CE Department

J. Strickland, ME Department

J. Lawrence, ME Department

Fred Thompson

Atari, Inc.

155 Moffett Park Drive

Sunnyvale, CA 94086
J. M. Turner, Group Leader

Terrestrial Energy Technology Program office

Energy Conversion Branch

Aerospace Power Division

Aero Propulsion Laboratory

Department of the Air Force

Air Force Wright Aeronautical Laboratories (AFSC)

Wright-Patterson Air Force Base, OH 45433

United Engineers and Constructors, Inc. Advanced Engineering Department

30 South 17 th Street

Philadelphia, PA 19101

Attn: A. J. Karalis

University of New Mexico (2)

New Mexico Engineering Research Institute

Campus P.O. Box 25

Albuquerque, NM 87131

Attn: D. E. Calhoun

G. G. Leigh

University of New Mexico

Albuquerque, NM 87106

Attn: K. T. Feldman

Energy Research Center

V. Sloglund

ME Department

Jan Vacek

Eolienne experimentale

C.P. 279, Cap-aux-Meules

Iles de la Madeleine, Quebec

CANADA

Irwin E. Vas

Solar Energy Research Institute

1.617 Cole Blvd.

Golden, CO 80401

Otto de Vries

National Aerospace Laboratory

Anthony Fokkerweg 2

Amsterdam 1017

THE NETHERLANDS

R. Walters

West Virginia University

Department of Aero Engineering

1062 Kountz Avenue

Morgantown, WV 26505

E. J. Warchol

Bonneville Power Administration

P.O. Box 3621

Portland, OR 97225 
D. F. Warne, Manager

Energy and Power Systems

ERA Ltd.

cleeve Rd.

Leather head

surrey KT22 7SA

ENGLAND

R. A. Watson

Stanford University

$546 \mathrm{~B}$ Crothers Memorial Hall

Stanford, $\mathrm{CA} \quad 94305$

R. J. Watson

Watson Bowman Associates, Inc.

$1280 \mathrm{Niagara}$ St.

Buffalo, NY 14213

R. G. Watts

Tulane University

Department of Mechanical Engineering

New or leans, Lñ 70018

Solar Energy Research Institute (3)

1617 Cole Blva.

Golden, CO 80401

Attn: Pat Weis

Library (2)

W. G. Wells, P.E.

Associate Professor

Mechanical Engineering Department

Mississippi State University

Mississippi State, MS 39762

T. Wentink, Jr.

University of Alaska

Geophysical Institute

Fairbanks, AK 99701

West Texas state University

Government Depository Library

Number 613

Canyon, TX 79015

Wind Energy Report

Box 14

$104 \mathrm{~S}$. Village Ave.

Rockville Centre, NY 11571

Attn: Farrell Smith Seiler

Richard E. Wong

Assistant Director

Central Solar Energy Research

Corporation

1200 Sixth Street

328 Executive Plaza

Detroit, MI 48226
1000

1200

3161

3161

4533

4700

4710

4715

4715

4715

4715

4715

4715

4715

4715

4715

5520

5521

5523

5523

5600

5620

5630

5632

5633

5633

8266

3141

3151
G. A. Fowler

I. D. Smith

J. E. Mitchell (15)

P. S. Wilson

J. W. Reed

J. H. Scott

G. E. Brandvold

R. H. Braasch (100)

J. D. Cyrus

R. D. Grover

E. G. Kadlec

P. C. Klimas

M. T. Mattison

R. O. Nellums

W. N. Sullivan

M. H. Worstell

T. B. Lane

D. W. Lobitz

R. C. Reuter, Jr.

T. G. Carne

D. B. Schuster

M. M, Newsom

R. C. Maydew

C. W. Peterson

S. McAlees, Jr.

R. E. Sheldahl

E. A. Aas

T. L. Werner (5)

W. L. Garner (3)

For DOE/TIC (Unlimited Release) 